\title{
An Alginate/Cyclodextrin Spray Drying Matrix to Improve Shelf Life and Antioxidant Efficiency of a Blood Orange By-Product Extract Rich in Polyphenols: MMPs Inhibition and Antiglycation Activity in Dysmetabolic Diseases
}

\author{
Maria Rosaria Lauro, ${ }^{1}$ Lucia Crascì, ${ }^{2}$ Virgilio Giannone, ${ }^{2,3}$ Gabriele Ballistreri, ${ }^{4}$ \\ Simona Fabroni, ${ }^{4}$ Francesca Sansone, ${ }^{1}$ Paolo Rapisarda, ${ }^{4}$ Anna Maria Panico, ${ }^{2}$ \\ and Giovanni Puglisi ${ }^{2}$ \\ ${ }^{1}$ Department of Pharmacy, University of Salerno, Via Giovanni Paolo II, 84084 Fisciano, Italy \\ ${ }^{2}$ Department of Drug Science, University of Catania, Viale A. Doria, 95100 Catania, Italy \\ ${ }^{3}$ Department of Agricultural and Forest Sciences, University of Palermo, Viale delle Scienze Ed.4, 90128 Palermo, Italy \\ ${ }^{4}$ Consiglio per la Ricerca in Agricoltura e l'Analisi dell'Economia Agraria (CREA) - Centro di ricerca Olivicoltura, \\ Frutticoltura e Agrumicoltura, Corso Savoia, 190, 95024 Acireale, Italy
}

Correspondence should be addressed to Maria Rosaria Lauro; lauro@unisa.it

Received 30 June 2017; Accepted 20 September 2017; Published 2 November 2017

Academic Editor: Anna V. Queralt

Copyright ( 2017 Maria Rosaria Lauro et al. This is an open access article distributed under the Creative Commons Attribution License, which permits unrestricted use, distribution, and reproduction in any medium, provided the original work is properly cited.

\begin{abstract}
Alginate and $\beta$-cyclodextrin were used to produce easily dosable and spray-dried microsystems of a dried blood orange extract with antidysmetabolic properties, obtained from a by-product fluid extract. The spray-dried applied conditions were able to obtain a concentrate dried extract without the loss of AOA and with TPC and TMA values of $35-40 \%$ higher than that of the starting material. They were also effective in producing microparticles with $80-100 \%$ of encapsulation efficiency. The $2 \%$ sodium alginate was capable of improving the extract shelf life, while the beta-cyclodextrin (1:1 molar ratio with dried extract) prolonged the extract antioxidant efficiency by 6 hours. The good inhibition effect of the dried extract on the AGE formation and the MMP-2 and MMP-9 activity is presumably due to a synergic effect exerted by both anthocyanin and bioflavonoid extract compounds and was improved by the use of alginate and cyclodextrin.
\end{abstract}

\section{Introduction}

The term "food by-products" indicates that "food wastes" are ultimate substrates for the recovery of functional compounds, as phytochemicals, to develop new products with additional value [1]. Blood orange processing wastes still contain large amounts of anthocyanins, bioflavonoids, and other polyphenols [2]. Many of these compounds are known for their antioxidant effect depending on their concentration [3-5] and their ability to inhibit the metalloproteinase
(MMP) activity [6] as MMP-2 and MMP-9, overexpressed during dysmetabolic diseases. In addition, a recent study reported the ability of dietary polyphenols to lower the advanced glycation end product (AGE) formation and protein glycation [7]. For these reasons, phytochemicals may be considered potential bioactive additives for functional food to prevent dysmetabolic pathologies. So, they could be conveniently recovered for nutraceutical purposes.

Our focus was on a Sicilian blood (pigmented or red) orange (cv. "Moro," "Tarocco," and "Sanguinello") by- 
product fluid extract $(\mathrm{ExF})$ potentially active on dyslipidemic pathologies $[8,9]$.

Unfortunately, the fluid extracts are difficult to handle from industry and are more unstable with respect to a dried product. In fact, phytochemical content easily oxidizes/ degrades [10]. To overcome this problem, a spray-dried extract (ExMR) was produced. The spray drying technique is able to prevent the appreciable losses of the extract's bioactive compounds without altering the health potential of the extract [11]. To protect phytochemicals from oxidation/degradation phenomena and enhance extract bioavailability, shelf life, and antioxidant efficiency, bioactive ExMR microparticles easily added to common foods of daily diet to enhance the patient compliance were obtained. As carriers, edible biocompatible films and coatings present in the GRAS list and able to deliver several vitamins, antioxidants, and probiotics in food systems [12] were chosen.

In particular, sodium alginate (ALG) is a water-soluble polymer capable of forming a hydrogel polymer matrix which allows a good diffusion of the bioactive compounds. Moreover, several studies showed that treatments with sodium alginate mitigate the glucose excursions, reduce insulin responses, increase satiety, and decrease energy intake and obesity $[13,14]$. For its activities, ALG can be used in synergy with the extract in dyslipidemic diseases such as obesity, diabetes, and hypercholesterolemia. Instead, $\beta$ cyclodextrin $(\mathrm{CD})$ and its derivatives are able to improve the physicochemical properties of the guest molecules [15], such as degradation and solubility [16], also masking their bitter taste [17].

In our study, solubility, solid state, dissolution properties, and shelf life of microparticle-loaded extract were studied and compared to those of the fluid extract to evaluate the effectiveness of the used spray drying technique. The influence of parameters such as the polymer concentration and the extract/polymer ratio on particle yield, distribution, and morphology was also investigated. Furthermore, the extract protection efficacy of the used selected coated polymers has been evaluated. Considering the synergistic involvement of free radicals, AGEs and MMPs on the onset of dysmetabolic diseases [18], the antioxidant activity (ORAC assay), the antiglycation activity, and the inhibition capacity on MMP-2 and MMP-9 (gelatinases involved in vascular remodeling with a consequence of high levels of cholesterol and triglycerides) $[6,19]$ of both formulated and unformulated extracts have been evaluated.

\section{Materials and Methods}

2.1. Materials. The fluid aqueous extract obtained from blood orange processing wastes $(\mathrm{ExF})$ was produced by Ortogel SpA (Caltagirone, Sicily, Italy). Beta-cyclodextrin was supplied by Roquette Frères (Lestrem, France). Sodium alginate (ALG), fluorescein (FL), AAPH $\left(2,2^{\prime}\right.$ azobis(2methylpropionamide) dihydrochloride) 97\%, Trolox (6hydroxy-2,5,7,8-tetramethylchroman-2-carboxylic acid) and HEPES (4-(2-hydroxyethyl)piperazine-1-ethanesulfonic acid), aminoguanidine bicarbonate $97 \%$ (AMG), bovine serum albumin (BSA), D-(-)-fructose, and sodium azide
$\left(\mathrm{NaN}_{3}\right)$ were purchased from Sigma-Aldrich Srl (Milan, Italy). Anthocyanins (cyanidin-3-glucoside, cyanidin-3, 5-diglucoside, cyanidin-3-rutinoside, and cyanidin-3sophoroside;delphinidin-3-glucoside and delphinidin-3,5diglucoside; pelargonidin-3-glucoside and pexlargonidin3,5-diglucoside; peonidin-3-glucoside; and malvidin-3-glucoside) and flavanones (hesperidin, narirutin, and didymin) were purchased from Extrasynthèse (Genay, France). OmniMMP fluorescent substrate Mca-Pro-Leu-Gly-LeuDpa-Ala-Arg- $\mathrm{NH}_{2}$, MMP-9 (refolded) (human) (recombinant) (catalytic domain) and MMP-2 (catalytic domain) (human) (recombinant) were purchased from VinciBiochem Srl (Firenze, Italy). Solvents for chromatography were HPLC grade (Merck KGaA, Darmstadt, Germany). All the other chemicals used in the study were of analytical grade and were obtained commercially.

2.2. Manufacture of Spray-Dried ExMR Product. A Buchi Mini Spray Dryer B-191 (Buchi Laboratoriums-Tecnik, Flawil, Switzerland) was used for the drying process: inlet temperature, $120^{\circ} \mathrm{C}$; outlet temperature, $68-71^{\circ} \mathrm{C}$; spray flow feed rate, $5 \mathrm{ml} / \mathrm{min}$; nozzle diameter, $0.7 \mathrm{~mm}$; drying air flow, $500 \mathrm{l} / \mathrm{h}$; air pressure, $6 \mathrm{~atm}$; and $100 \%$ aspirator.

\subsection{Qualitative and Quantitative Analyses of Bioactive Compounds in Fluid (ExF) and Spray-Dried Aqueous Extract (ExMR)}

2.3.1. Qualitative Analysis. Anthocyanin Purification and HPLC-PDA-ESI/MSn Analysis of Anthocyanins. The extracts were diluted in water for HPLC analysis of anthocyanins. Aqueous extracts were loaded onto C18 Bond Elut SPE cartridges (Varian Inc., Palo Alto, CA, USA) that were previously conditioned with methanol and pure water. The anthocyanins were adsorbed by these cartridges while other soluble compounds such as sugars and acids were removed by washing the columns with pure water. Anthocyanins were eluted with methanol containing $1 \%$ formic acid. The acidified methanol solutions were evaporated to dryness; then, the dried fractions were redissolved in $7 \%$ aqueous formic acid. Then, the samples were filtered through a $0.45 \mu \mathrm{m}$ membrane filter (Albet, Barcelona, Spain) and injected into the HPLC-MS ${ }^{n}$ chromatographic system to identify the individual anthocyanins.

Evaluation of anthocyanins was performed on a Chromolith Performance RP-18 endcapped column $(100 \times 3.0 \mathrm{~mm}$ i.d., monolithic particle size; Merck KGaA, Darmstadt, Germany) using an ultrafast HPLC system coupled to a photodiode array (PDA) detector and Finnigan LXQ ion trap equipped with an electrospray ionization (ESI) interface in series configuration (Thermo Electron, San Jose, CA, USA). HPLC conditions and MS parameters were reported as the same in a previous work [20]. Anthocyanins were identified by using their retention time (tR), MS, and $\mathrm{MS}^{n}$ spectral data in a positive ion mode. In addition, comparison of the MS spectral data with those of pure standards and/or those reported in literature was performed. The relative compositions (\%) of the individual anthocyanins were calculated from the peak areas of the 
chromatogram detected at $520 \mathrm{~nm}$, using Xcalibur versus 2.0.7 software (Thermo Electron).

HPLC-PDA-ESI/MSn Analysis of Flavanones. Flavanone glycosides, expressed as hesperidin ( $\mathrm{Hd}$ ) equivalents (g/100 g of extract), were determined by HPLC [21] using the HPLC-PDA-ESI/MS ${ }^{n}$ equipment described above. A sample of the extract was dissolved in dimethyl sulfoxide and diluted with the mobile phase, filtered through a $0.45 \mu \mathrm{m}$ membrane filter (Albet, Barcelona, Spain), and then injected directly into the column. The eluent was water:acetonitrile:acetic acid (79.5:20:0.5), and the flow rate was $800 \mu \mathrm{l} / \mathrm{min}$. The individual flavanones were detected at $280 \mathrm{~nm}$. MS parameters were the same as those described for anthocyanin analysis. Flavanones were identified by using their retention time (tR), MS, and $\mathrm{MS}^{n}$ spectral data in a negative ion mode and also by comparison of the MS data with those of pure standards and/or those reported in literature.

2.3.2. Quantitative Analysis. Total Polyphenol Content (TPC). The polyphenol contents of ExF and ExMR were determined by the Folin-Ciocalteau method according to Aiyegoro and Okoh [22], with slight modifications. $2 \mathrm{mg} / \mathrm{ml}$ of both extracts was dissolved in distilled water. Then, $2.5 \mathrm{ml}$ of $10 \%$ Folin-Ciocalteau reagent and $2 \mathrm{ml}$ of $\mathrm{Na}_{2} \mathrm{CO}_{3}(2 \% \mathrm{w} / \mathrm{v})$ were added to $0.5 \mathrm{ml}$ of each samples. The resulting mixtures were incubated at $45^{\circ} \mathrm{C}$ with shaking for $15 \mathrm{~min}$. The absorbance of the samples was measured at $765 \mathrm{~nm}$ using UV/visible light. The standard curve $(y=4.292$ $\left.-0.0293 x ; R^{2}=0.9951\right)$ was prepared by $0,0.05,0.1,0.15$, 0.2 , and $0.25 \mathrm{mg} \cdot \mathrm{ml}^{-1}$ solutions of gallic acid in water. TPC values are expressed as milligram of gallic acid equivalents (GAE)/g of extract.

Total Monomeric Anthocyanin (TMA) Content. TMA content was assayed by the $\mathrm{pH}$ differential method [23] by using a UV/Vis spectrophotometer (Varian Cary 100 Scan, Palo Alto, CA, USA). Total anthocyanin content was expressed as $\mathrm{g}$ of cyanidin-3-glucoside equivalents $(\mathrm{C} 3 \mathrm{G}) / 100 \mathrm{~g}$ of extract on a dry weight (DW) basis.

\subsection{Solubility Studies}

2.4.1. ExMR Solubility. Solubility test of dried ExMR was performed in distilled water $(3.0 \pm 0.2 \mathrm{~g} / \mathrm{l})$ and in gastric (GF; pH 1.2) (3.5 $\pm 0.1 \mathrm{~g} / \mathrm{l})$ and intestinal (IF; pH 7.5) (3.8 $\pm 0.2 \mathrm{~g} / \mathrm{l}$ ) simulated fluids, without enzymes (USP 37) by $\mathrm{UV} / \mathrm{V}$ is spectrometry at $\lambda=310 \mathrm{~nm}$ and expressed as hesperidin equivalents (Hd). Each analysis was made in triplicate.

2.4.2. Phase Solubility. $2.5 \times 10^{3} \mathrm{~mol}$ of ExMR, expressed as $\mathrm{Hd}$, was suspended in $100 \mathrm{ml}$ of water. Different amounts [24] of $\operatorname{CD}(1: 3,1: 2,1: 1.5,1: 1$, and $2: 1$ ExMR/CD molar ratio) were added. The samples were shaken, stored at $25^{\circ} \mathrm{C}$ for 1 hour, and then centrifuged $(5 \mathrm{~min}$ at $3000 \mathrm{rpm})$. The supernatants were analyzed in UV apparatus ( $1 \mathrm{~cm}$ cell; $\lambda=278 \mathrm{~nm}$ ).

2.5. Microparticle Preparation. ExMR was suspended (3:1 polymer : extract weight ratio) in $1 \%$ or $2 \%(w / v)$ ALG aqueous solution, under magnetic stirring [25], to give the ExMR1 (1\% ALG) and ExMR2 (2\% ALG) microsystems. In the second step, CD (1:1 CD:ExMR molar ratio) was dissolved in 2\% $w / v$ ALG water solution (3:1 ALG:ExMR weight ratio), to obtain ALGCDExMR microparticles. ALG-free microparticles (CDExMR) were used as control. The spray drying conditions were reported as the same in ExMR preparation. All the spray-dried microparticles were carried out in triplicate, collected, and stored under vacuum ( $48 \mathrm{~h}$ at room temperature).

\subsection{Microparticle Properties and Characterization}

2.6.1. Particle Size Analyses. Isopropanol was used as a suspending agent for all samples. A Beckman Counter LS 230, Particle Volume Module Plus, UK (instrument obscuration: $8-12 \%)$, was used to examine the particle size in triplicate applying the Fraunhofer model. The results were expressed as the median diameter of the particles $(\mathrm{d} 50)$.

2.6.2. Morphology. The microphotographs of the morphology of all samples were acquired by a confocal (Leica TCS SP2, $\mathrm{CF}$ ) and a fluorescent microscope (Zeiss Axiophot, FM).

All images were equipped with $63 \times 1.4 \mathrm{NA}$ plan apochromat oil immersion objectives (Carl Zeiss Vision, München-Hallbergmoos, Germany) and standard DAPI (4',6-diamidino-2-phenylindole) optics that adsorb violet radiation $(\max 372 \mathrm{~nm})$ and emit blue fluorescence $(\max 456 \mathrm{~nm})$.

2.6.3. Yield of the Process (Y), Encapsulation Efficiency (EE), and Extract Content in Microsystems. Y was gravimetrically determined and expressed as the weight percentage of the final product compared to the total amount of the sprayed materials.

EE was calculated according to Sansone et al. [10].

$$
\mathrm{EE}(\%)=\frac{\text { actual extract content }}{\text { theoretical extract content }} \text {. }
$$

The actual extract content was calculated as Hd concentration used as a marker and determined in the supernatant solutions of $15 \mathrm{mg}$ of microsystems dissolved in $\mathrm{MeOH}$ $(15 \mathrm{ml}$; sonicated for $5 \mathrm{~min}$, centrifuged for $10 \mathrm{~min}$ at $300 \mathrm{rpm}$ ) by HPLC Agilent equipment (Agilent 1100 series system; model G-1312 pump; Rheodyne Model G-1322A loop $(20 \mu \mathrm{l})$; DAD G-1315 detector; $150 \times 3.9 \mathrm{~mm}$ i.d. C18 $\mu$-Bondapack column). The flow rate is $1.0 \mathrm{ml} \cdot \mathrm{min}^{-1}$. The following are the mobile phases: water (solvent A) and methanol (solvent B). The elution gradient was shown as follows: $0 \rightarrow 5 \mathrm{~min}(15 \rightarrow 30 \%) \mathrm{B}, 5 \rightarrow 10 \mathrm{~min}(30 \rightarrow 35 \%)$ $\mathrm{B}, 10 \rightarrow 20 \mathrm{~min}(35 \rightarrow 50 \%) \mathrm{B}, 20 \rightarrow 30 \mathrm{~min}(50 \rightarrow 75 \%) \mathrm{B}$, $30 \rightarrow 35 \mathrm{~min}(75 \rightarrow 95 \%) \mathrm{B}$, and $35 \rightarrow 40 \mathrm{~min}(100 \%) \mathrm{B}$. A DAD detector was set at $\lambda=283 \mathrm{~nm}$. Hd reference standard solutions were prepared at five concentration levels in the range $1-40 \mu \mathrm{g} / \mathrm{ml}$. Linear least squares regression equation was derived from the peak area corresponding to $\mathrm{Hd}$ $(y=1798.3 x-54.938, R=0.9996)$, where $y$ is the peak area and $x$ the used concentration.

2.6.4. Differential Scanning Calorimetry (DSC) and FourierTransform Infrared Spectroscopy (FTIR). DSC. An indiumcalibrated Mettler Toledo DSC822e (OH, USA) was used 
exposing all the samples to two thermal cycles: a dehydration cycle up to $130^{\circ} \mathrm{C}$ (heating rate of $20^{\circ} \mathrm{C} / \mathrm{min}$; temperature maintained at $130^{\circ} \mathrm{C}$ for $15 \mathrm{~min}$ in order to remove the residual solvent); afterwards, the samples were cooled at $25^{\circ} \mathrm{C}$ and heated up to $350^{\circ} \mathrm{C}$ (heating rate of $10^{\circ} / \mathrm{min}$ ) [6]. The analyses were carried out in triplicate.

FTIR. A Jasco FT-300 (Tokyo, Japan) Fourier-transform IR spectrometer was used to analyze all samples in two steps: first, the material was dried in a vacuum oven to reduce the presence of water and then analyzed as $\mathrm{KBr}$ discs in the spectral region $650-4,000 \mathrm{~cm}^{-1}$ at a resolution of $8 \mathrm{~cm}^{-1}$.

\subsection{Stability Studies}

2.7.1. Accelerated Stability. The stability test was performed according to accelerated stability studies reported in the ICH guidelines (International Conference on Harmonization of Technical Requirements of Pharmaceutical for Human Use, 2003) in a climatic and thermostatic chamber (Mod.CCP37, AMT srl, Milan, Italy), at $40^{\circ} \mathrm{C} \pm$ $2^{\circ} \mathrm{C} / 75 \% \mathrm{RH} \pm 5 \% \mathrm{RH}$ for one week and then analyzed by UV and HPLC in terms of extract content and TPC variation. Chromatographic peaks were identified on the basis of the retention times and confirmed by coinjections with an internal standard [14].

2.7.2. Functional Stability (Oxygen Radical Absorbance Capacity: ORAC Assay). In order to determine the in vitro antioxidant capacities of both ExF and ExMR, the ORAC method [26] was employed. Also, a comparison between ORAC unprocessed (ExMR) and processed extract by $\mathrm{ICH}$ (ExMR ICH) was performed.

The fluorescence probe fluorescein (FL, $10 \mathrm{nM})$ was used as a reference compound attacked from peroxyl free radicals that are generated from APPH $(100 \mathrm{mM})$ solution. In order to calculate the area under a curve (AUC) of the tested compounds $(12.5 \mu \mathrm{g} / \mathrm{ml})$, the reaction was following at $37^{\circ} \mathrm{C}$ (pH 7.0) until a fluorescence decay of FL solution in the presence of APPH. Each measurement was repeated at least three times, using a Wallac 1420 Victor 96-well plate reader (PerkinElmer, USA) with a fluorescence filter (excitation $485 \mathrm{~nm}$, emission $520 \mathrm{~nm})$. The Trolox $(12.5 \mu \mathrm{M})$ was used as an antioxidant control.

The ORAC value refers to the net protection area under the quenching curve of fluorescein in the presence of an antioxidant. The final results (ORAC value) were calculated and expressed in ORAC units (Trolox micromol per microgram of sample $(\mu \mathrm{mol} / \mu \mathrm{g}))$.

$$
\text { ORAC value }(\mu \mathrm{mol} / \mu \text { gram })=\frac{K(S \text { sample }-S \text { blank })}{(S \text { Trolox }-S \text { blank })},
$$

where $K$ is a sample dilution factor and $S$ is the area under the fluorescence decay curve of the sample, Trolox or blank, calculated with Origin ${ }^{\circledR 7}$ (OriginLab Corporation, Northampton, USA).

2.8. In Vitro Dissolution/Release Tests. ExMR (100 mg, sink conditions) or produced formulation corresponding to the same amount of pure dried extract was carried out under sink conditions (corresponding to about) in water using a SOTAX AT smart apparatus (Basel, $\mathrm{CH}$ ), on a line with a spectrophotometer at $\lambda=310$ (UV/Vis spectrometer Lambda 25, PerkinElmer Instruments, MA, USA), and USP 37 dissolution test apparatus n.2: paddle, $100 \mathrm{rpm}$ at $37^{\circ} \mathrm{C}$. All the dissolution/release tests were made in triplicate; only the mean values are reported in a graph (standard deviations $<5 \%$ ).

2.9. Antioxidant Efficiency. To determine the antioxidant efficiency of formulated and unformulated samples, a modified ORAC assay was used [6]. Briefly, both $25 \mu$ l extracts of all samples were placed in 96-well tissue culture plates. $100 \mu \mathrm{l}$ FL $(10 \mathrm{nM})$ solution was added to each well to initiate the assay. Then, $25 \mu \mathrm{l}$ AAPH $(100 \mathrm{mM})$ solution was added to all wells, except for the negative control, to which $25 \mu \mathrm{l}$ phosphate buffer solution was added. A FL solution without AAPH was used as negative control. A timer was started upon introduction of the free radical generator, and the plate was stored in the dark at $37^{\circ} \mathrm{C}$. Unlike the previous method (reported in paragraph 2.7.2.), at each specified time point, the fluorescence of the solution was measured (excitation $492 \mathrm{~nm}$, emission $535 \mathrm{~nm}$ ) and plotted as a function of time [27, 28], using Origin7 (OriginLab Corporation, Northampton, USA). The $y$-axis graphs in Figure 1 were split from 6000 to 10000 RFU.

2.10. Antiglycation Activity. According to the method of Derbré et al. [29] with slight modifications, we evaluated the inhibition of fluorescence produced by AGE formation through Maillard reaction. Briefly, as optimum AGE formation, the protein model bovine serum albumin (BSA) $(10 \mathrm{mg} / \mathrm{ml})$ was incubated with $\mathrm{D}$-fructose $(0.5 \mathrm{M})$ in phosphate buffer $50 \mathrm{mM}$ pH $7.4\left(\mathrm{NaN}_{3} 0.02 \%\right)$ to obtain positive controls. BSA alone was the negative control corresponding to no fluorescence AGE formation. The aminoguanidine (AMG) $(400 \mu \mathrm{g} / \mathrm{ml})$ was used as reference compounds for its AGE inhibition property [30]. The final glycated BSA solutions $(300 \mu \mathrm{L})$ alone and with the sample $(400 \mu \mathrm{g} / \mathrm{mL})$ were incubated at $37^{\circ} \mathrm{C}$ in a 96 -well microtiter closed with their silicon lids for 7 days. The AGE fluorescence measurement ( $\lambda$ exc $370 \mathrm{~nm}$; $\lambda$ em $440 \mathrm{~nm}$ ) is performed using a VICTOR Wallac 1420 Multilabel Counter fluorimeter (PerkinElmer, USA). The results are reported in relative fluorescence units (RFU), and the percentage of inhibition with respect to the positive control (BSA with fructose) is calculated from the following equation:

$$
\% \text { of inhibition }=\left\{1-\frac{\mathrm{RFU} \text { sample }(\mathrm{nm})}{\mathrm{RFU}-\text { positive control }(\mathrm{nm})}\right\} \times 100 .
$$

\subsection{Inhibitory Activity on MMP-2 and MMP-9. The MMP} inhibition assay of unformulated and formulated ExMR was based on the inhibition of the hydrolysis of the fluorescence-quenched peptide substrate Mca-Pro-Leu-GlyLeu-Dpa-Ala-Arg- $\mathrm{NH}_{2}$ (Vinci-Biochem Srl). The assay was performed according to Crascì et al. [31]. The results were plotted with Origin7 (Originlab Corporation, Northampton, 


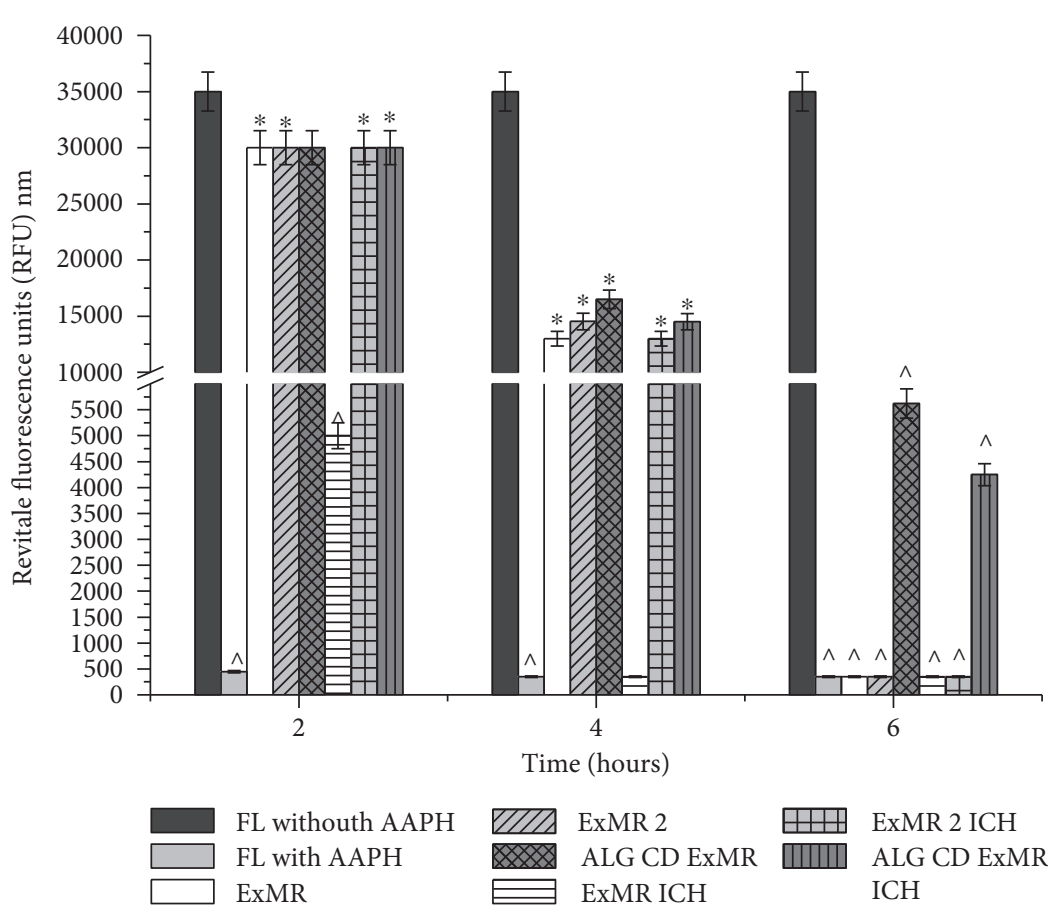

FIGURE 1: Antioxidant efficiency of unformulated and formulated extracts. Data represent the mean of three independent experiments \pm SD. ${ }^{*} p<0.05$ or ${ }^{\wedge} p<0.01$ compared with FL without AAPH. ICH: samples processed according to ICH guidelines.

USA) software and are expressed as concentration of inhibitors that reduced of $50 \%$ the MMPs activity $\left(\mathrm{IC}_{50}\right)$.

\section{Results and Discussion}

3.1. Characterization and Stability of Unprocessed (ExF) and Processed (ExMR) Extracts. Both the extracts (ExF and ExMR) were analyzed by HPLC-MS and showed four major eluted constituents (Tables 1 and 2), two anthocyanins, cyanidin 3-(6"-malonyl) glucoside (CMG, $\left.t_{\mathrm{R}} 18.9 \mathrm{~min}\right)$ and cyanidin 3-glucoside (C3G, $t_{\mathrm{R}} 15.2 \mathrm{~min}$ ) and two $O$-glycosylated flavonoids, hesperidin $\left(\mathrm{Hd}, t_{\mathrm{R}} 18.5 \mathrm{~min}\right)$ and narirutin $\left(\mathrm{Nr}, t_{\mathrm{R}} 13.5 \mathrm{~min}\right.$ ) (Figure 2).

In agreement with previous data reported in literature $[32,33]$, the major component $\mathrm{Hd}$ was chosen as marker [6]. Both Hd and C3G, as bioflavonoid and anthocyanin markers, respectively, were used as comparison compounds to determine the bioactive content in MMP studies.

The analytic data of ExF showed that the TPC (Table 3) and TMA values were equal to $35 \%$ and $40 \%$ of the spray-dried ExMR extract, respectively. In fact, in ExF, the levels of TPC (mg gallic acid/g extract) and TMA (\%) were $12.0 \pm 0.18 \mathrm{mg} / \mathrm{g}$ and $0.322 \pm 0.02 \%$, respectively. The antioxidant activity (Table 3 ) expressed in ORAC units (AOA) was $1.9 \pm 0.8$ ORAC units. The evaluation of the extract properties is essential to obtain spraydried powders with optimized physicochemical and biological properties.

3.2. Spray Drying Process. ExF has been spray dried to obtain a powder extract which can be easily handled. The spray drying technique is the most commonly used in food and nutrapharmaceutical industries [34]. It is a crucial step that can affect the extract stability [35] and plays an important role in determining the properties and cost of dried products [36]. On this consideration, it is interesting to note that the selected spray dryer conditions were able to obtain a product yield equal to $60 \%$ and without loss of AOA activity (2.6 \pm 0.3 ORAC units). Furthermore, the TPC and TMA values $(33.5 \pm 0.21 \mathrm{mg} / \mathrm{g}$ and $0.814 \pm 0.1 \%$, resp.) were higher than that of ExF. These results are probably due to the spray drying parameters such as the inlet temperature $\left(120^{\circ} \mathrm{C}\right)$ which were optimized in order to protect and reduce the loss of polyphenols because of degradation [25].

3.3. Solubility Studies. ExMR has a slight water solubility $(3.0 \pm 0.1 \mathrm{mg} / \mathrm{l})$ at room temperature that was notably affected by the presence of $\mathrm{CD}$ used as enhancer of dissolution rate, limiting factor of in vivo bioavailability.

The amount of $\mathrm{CD}$ required to increase a sample bioavailability can be evaluated by the phase solubility studies and can affect the various processes occurring during the delivery in the gastrointestinal (GI) environment [37].

The phase solubility (Figure 3) showed a Bs-type profile [24]. CD is capable to enhance the ExMR solubility with a linear increase below the $1: 2 \mathrm{ExMR} / \mathrm{CD}$ molar ratio. The ascending portion indicates a $1: 1$ stoichiometry complex; at higher $\mathrm{CD}$ concentrations appears a short plateau indicating the formation of an insoluble or with a different stoichiometry complex in the solution. For this reason, conventionally, we assumed a 1:1 ExMR molar ratio to obtain an improvement of water solubility (from $3.0 \pm$ $0.1 \mathrm{mg} / \mathrm{l}$ to $6.0 \pm 0.5 \mathrm{mg} / \mathrm{l}$ ) and an enhancement of the 
TABLE 1: Total anthocyanin content of ExMR and ExF and relative percentage of individual anthocyanins.

\begin{tabular}{|c|c|c|c|c|c|c|}
\hline \multirow{2}{*}{ Peak number ${ }^{\mathrm{a}}$} & \multirow{2}{*}{$t_{\mathrm{R}}(\min )$} & \multirow{2}{*}{$(M)^{+}(\mathrm{m} / \mathrm{z})$} & \multirow{2}{*}{$\operatorname{MS}^{n}(\mathrm{~m} / \mathrm{z})$} & \multirow{2}{*}{ Anthocyanins } & \multicolumn{2}{|c|}{ Relative composition $^{\mathrm{b}}(\%)$} \\
\hline & & & & & ExMR & $\mathrm{ExF}$ \\
\hline 1 & 13.9 & 611 & $449 / 287$ & Cyanidin 3,5-diglucoside & $1.31 \pm 0.01$ & $1.72 \pm 0.08$ \\
\hline 2 & 14.2 & 465 & 303 & Delphinidin 3-glucoside & $2.65 \pm 0.02$ & $2.96 \pm 0.13$ \\
\hline 3 & 14.5 & 611 & 287 & Cyanidin 3-sophoroside & $0.51 \pm 0.01$ & $0.16 \pm 0.02$ \\
\hline 4 & 15.2 & 449 & 287 & Cyanidin 3-glucoside & $39.87 \pm 0.17$ & $31.80 \pm 0.06$ \\
\hline 5 & 15.9 & 595 & 287 & Cyanidin 3-rutinoside & $1.34 \pm 0.24$ & $0.43 \pm 0.10$ \\
\hline 6 & 16.8 & 479 & 317 & Petunidin 3-glucoside & $1.55 \pm 0.02$ & $1.53 \pm 0.02$ \\
\hline 7 & 17.5 & 551 & $465 / 303$ & Delphinidin 3-(6"-malonyl)glucoside & $1.53 \pm 0.01$ & $0.67 \pm 0.08$ \\
\hline 8 & 17.9 & 463 & 301 & Peonidin 3-glucoside & $2.88 \pm 0.03$ & $2.90 \pm 0.03$ \\
\hline 9 & 18.2 & 565 & $479 / 317$ & Petunidin 3-(6"-malonyl)glucoside & $1.48 \pm 0.01$ & $0.58 \pm 0.05$ \\
\hline 10 & 18.9 & 535 & $449 / 287$ & Cyanidin 3-(6"-malonyl)glucoside & $21.73 \pm 0.10$ & $36.40 \pm 0.05$ \\
\hline 11 & 19.9 & 593 & $449 / 287$ & Cyanidin 3-(6"-dioxalyl)glucoside & $5.91 \pm 0.03$ & $8.02 \pm 0.05$ \\
\hline 12 & 20.4 & - & 271 & Pelargonidin derivative & $1.23 \pm 0.01$ & $5.55 \pm 0.03$ \\
\hline 13 & 21.7 & 549 & $463 / 301$ & peonidin 3-(6"-malonyl)glucoside & $13.84 \pm 0.11$ & $5.81 \pm 0.12$ \\
\hline 14 & 22.2 & - & 287 & Cyanidin derivative & $2.35 \pm 0.03$ & $1.01 \pm 0.12$ \\
\hline 15 & 23.3 & - & 301 & Peonidin derivative & $1.82 \pm 0.02$ & $0.46 \pm 0.08$ \\
\hline \multicolumn{5}{|c|}{ Total anthocyanins $\left(\mathrm{g}\right.$ C3G/100 g extract) ${ }^{\mathrm{c}}$} & $0.81 \pm 0.01$ & $0.32 \pm 0.02$ \\
\hline
\end{tabular}

${ }^{a}$ The numbering is according to Figures 2 (a) and 2(b). ${ }^{b}$ Relative percentage of anthocyanins was based on HPLC peak areas recorded at $520 \mathrm{~nm} .{ }^{c}$ Anthocyanins are expressed as cyanidin 3 -glucoside equivalents.

TABLE 2: Concentration of individual flavanones and total flavanones in ExMR and ExF.

\begin{tabular}{|c|c|c|c|c|c|c|}
\hline \multirow{2}{*}{ Peak number ${ }^{\mathrm{a}}$} & \multirow{2}{*}{$t_{\mathrm{R}}(\min )$} & \multirow{2}{*}{$(M-H)^{-}(\mathrm{m} / \mathrm{z})$} & \multirow{2}{*}{$\mathrm{MS}^{n}(\mathrm{~m} / \mathrm{z})$} & \multirow{2}{*}{ Flavanones } & \multicolumn{2}{|c|}{$\mathrm{g} \mathrm{Hd} / 100 \mathrm{~g}^{\mathrm{b}}$} \\
\hline & & & & & ExMR & ExF \\
\hline 1 & 13.5 & 579 & 271 & Narirutin & $5.48 \pm 0.05$ & $2.22 \pm 0.06$ \\
\hline 2 & 18.5 & 609 & 301 & Hesperidin & $5.73 \pm 0.02$ & $2.35 \pm 0.11$ \\
\hline 3 & 59.9 & 593 & 285 & Didymin & $0.79 \pm 0.01$ & $0.33 \pm 0.02$ \\
\hline \multicolumn{5}{|c|}{ Total flavanones ( $\mathrm{g} \mathrm{Hd} / 100 \mathrm{~g}$ extract) ${ }^{\mathrm{b}}$} & $12.00 \pm 0.07$ & $4.90 \pm 1.13$ \\
\hline
\end{tabular}

${ }^{a}$ The numbering is according to Figures $2(\mathrm{c})$ and $2(\mathrm{~d}) .{ }^{\mathrm{b}}$ Flavanones are expressed as hesperidin equivalents.

dissolution rate of the extract, as confirmed by the dissolution/release test.

\subsection{Spray-Dried Microparticle Properties and Characterization}

3.4.1. Alginate Microparticles (ExMR1 and ExMR2). In the first step, in order to achieve stable microsystems, ExMR was spray dried using $1 \%$ or $2 \%$ ALG water solutions $w / v$ as coating polymer and $3: 1$ polymer: extract weight ratios. The best formulation was in the presence of $2 \%$ of ALG (ExMR2). The low amount (1\%) of ALG in ExMR1 produced microparticles with greater particle size $(5 \pm 0.8 \mu \mathrm{m})$ than ExMR2 $(1.5 \pm 0.5 \mu \mathrm{m})$, probably due to aggregate formation and high moisture content $[38,39]$ (Figure 4(a)). For this reason, 2\% of ALG formulation (ExMR2) were selected. The results showed that the selected parameters (spray drying conditions and 2\% of ALG) were able to produce well-formed microparticles (Figure 4(b)) and to obtain a good EE (80.0\%). These were due to the ALG amount, able to reduce in solid dispersion the molecular mobility of the bioactive compounds avoiding the phase separation, while the spray drying parameters were effective to lower the accumulation on the chamber wall [24, 40-43].

The ExMR2 DSC thermogram (Figure 5) did not show any extract peak, confirming its complete encapsulation, such as that supported by FTIR analysis. Moreover, ALG shows high decomposition temperature. In fact, the ALG thermogram exhibits a first endothermic peak at $100^{\circ} \mathrm{C}$ (correlated to the release of water) and an exothermic peak at $250^{\circ} \mathrm{C}$, due to pyrolysis reaction in the polymer [44]. Since, some food manufacturing processes, especially baked good production, required high cooking temperature $\left(150^{\circ}-200^{\circ} \mathrm{C}\right)$ [45]. The ALG thermal behavior of the produced formulation could be suitable to protect the loaded active ingredient also to prevent the premature crystallization of the sugars [46] present in the extract.

$2 \%$ ALG water solution is also able to improve the dissolution rate of ExMR (Figure 6). In fact, about $49 \%$ of the extract were released from ExMR2 in 5 min with respect to about $16 \%$ of pure extract that dissolved at the same time. 
Anthocyanins

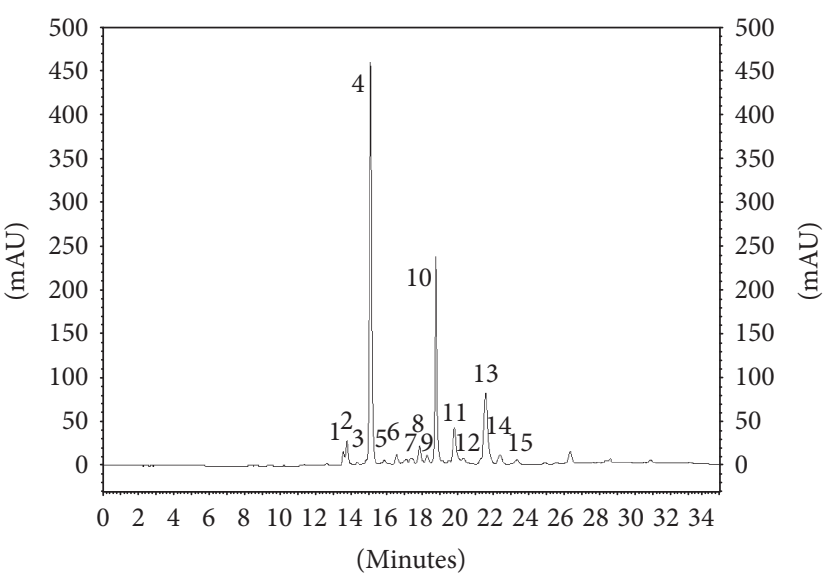

(a)

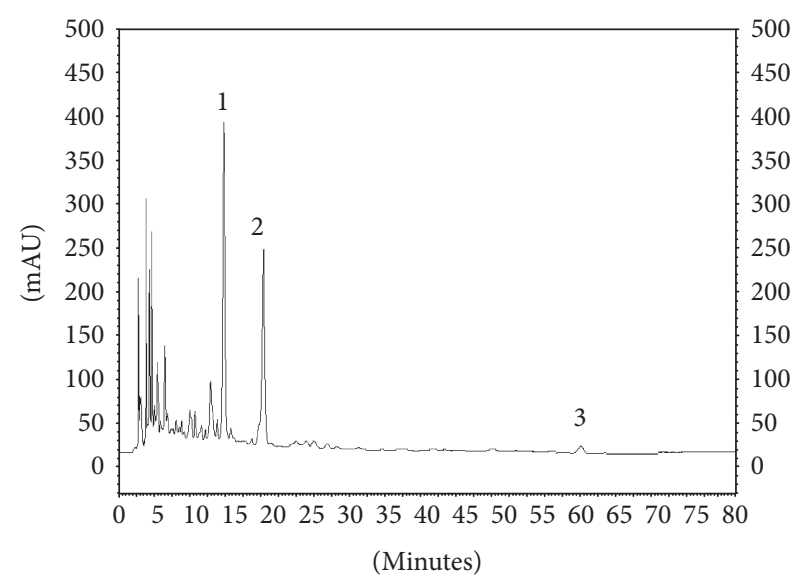

(c)

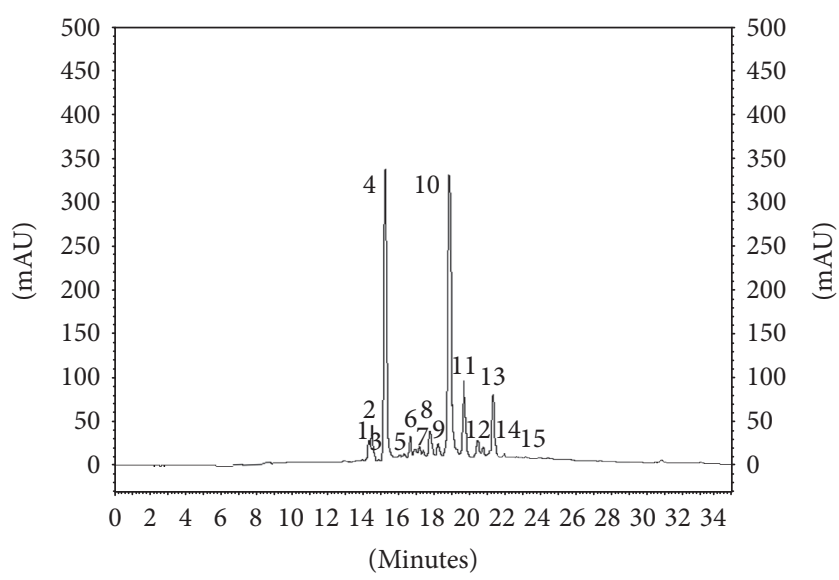

(b)

Flavanones

Figure 2: HPLC chromatograms of anthocyanins of ExMR (a) and ExF (b) detected at $520 \mathrm{~nm}$ (see Table 1). HPLC chromatograms of flavanones of ExMR (c) and ExF (d) detected at $280 \mathrm{~nm}$ (see Table 2).

TABLE 3: Quantitative antioxidant activity (ORAC assay) and total polyphenol content (TPC) of fluid extract (ExF), spray-dried extract (ExMR), and spray-dried extract processed according to ICH guidelines (ExMR ICH).

\begin{tabular}{lcc}
\hline Sample & $\begin{array}{c}\text { TPC } \\
(\mathrm{mg} \text { GAE/g of extract })\end{array}$ & $\begin{array}{c}\text { ORAC units } \\
(\mu \mathrm{mol} \mathrm{TE} / \mu \mathrm{g} \text { of extract })\end{array}$ \\
\hline ExF & $12.00 \pm 0.18$ & $1.90 \pm 0.80^{*}$ \\
ExMR & $33.50 \pm 0.21$ & $2.60 \pm 0.30^{*}$ \\
ExMR ICH & $28.80 \pm 0.60$ & $0.70 \pm 0.08^{*}$ \\
\hline
\end{tabular}

Reported values are the means \pm standard deviation (SD) $(n=3)$. *Significantly different at $p<0.05$ compared to 1 ORAC unit of Trolox.

This behavior was probably due to the presence of ALG that increase the extract-water interaction due to its high hydrophilic behavior $[6,13]$. Because extract-water release was incomplete (Figure 6) (85\% in $30 \mathrm{~min}$ ), in the second step, microparticles with enhancement of the dissolution rate were developed in the presence of CD.

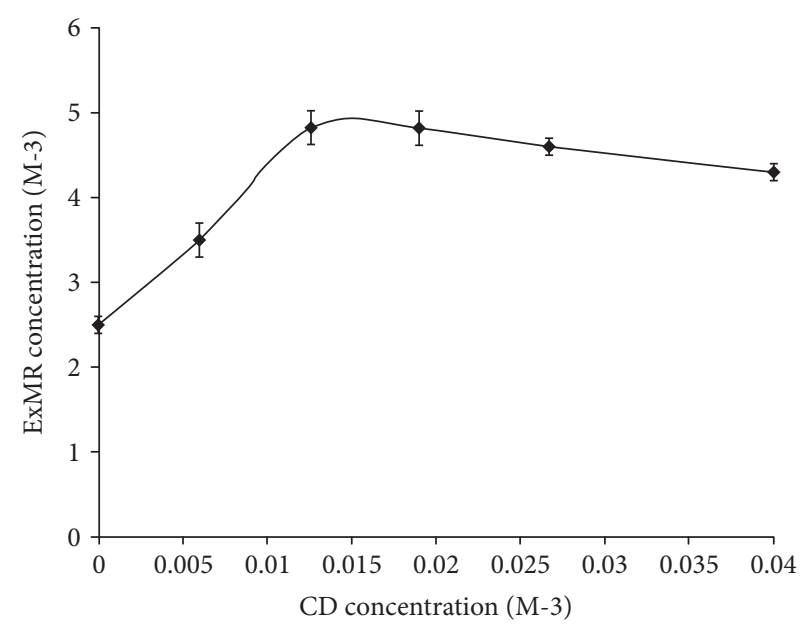

FIGURE 3: Solubility phase diagram of ExMR in the presence of $\beta$-cyclodextrin. 


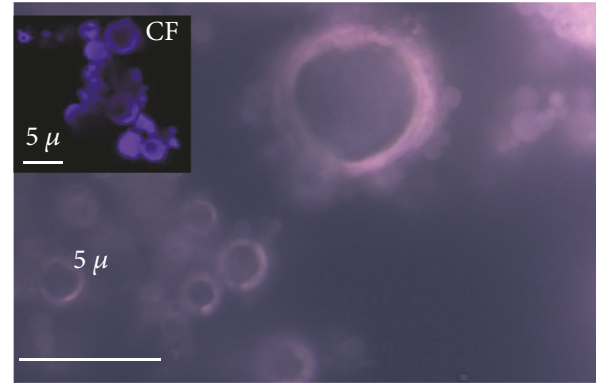

(a)

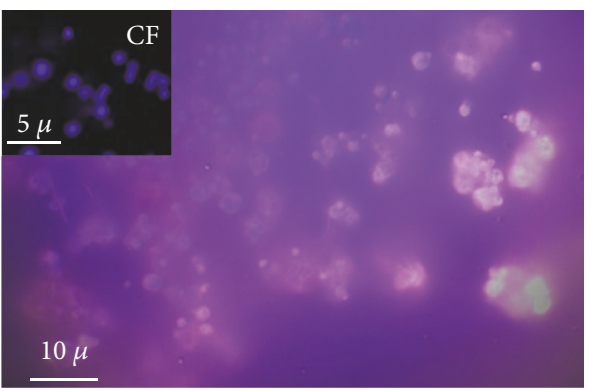

(c)

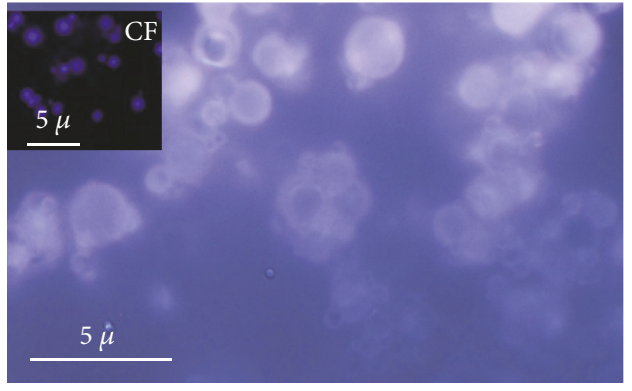

(b)

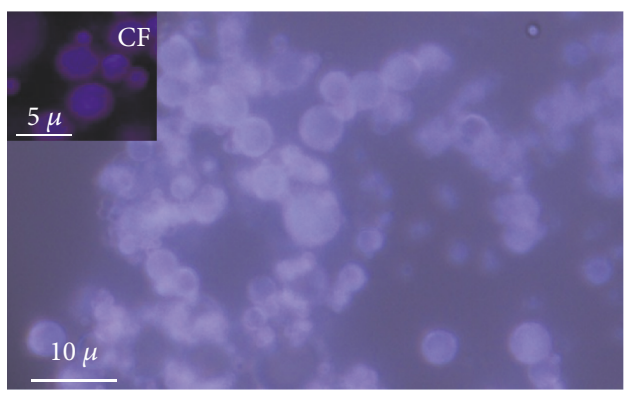

(d)

Figure 4: Fluorescence $(F M, \times 63$ and $\times 40)$ and confocal $(\mathrm{CF})$ microphotographs of ExMR1 (a), ExMR2 (b) CDExMR (c), and ALGCDExMR (d) microsystems.

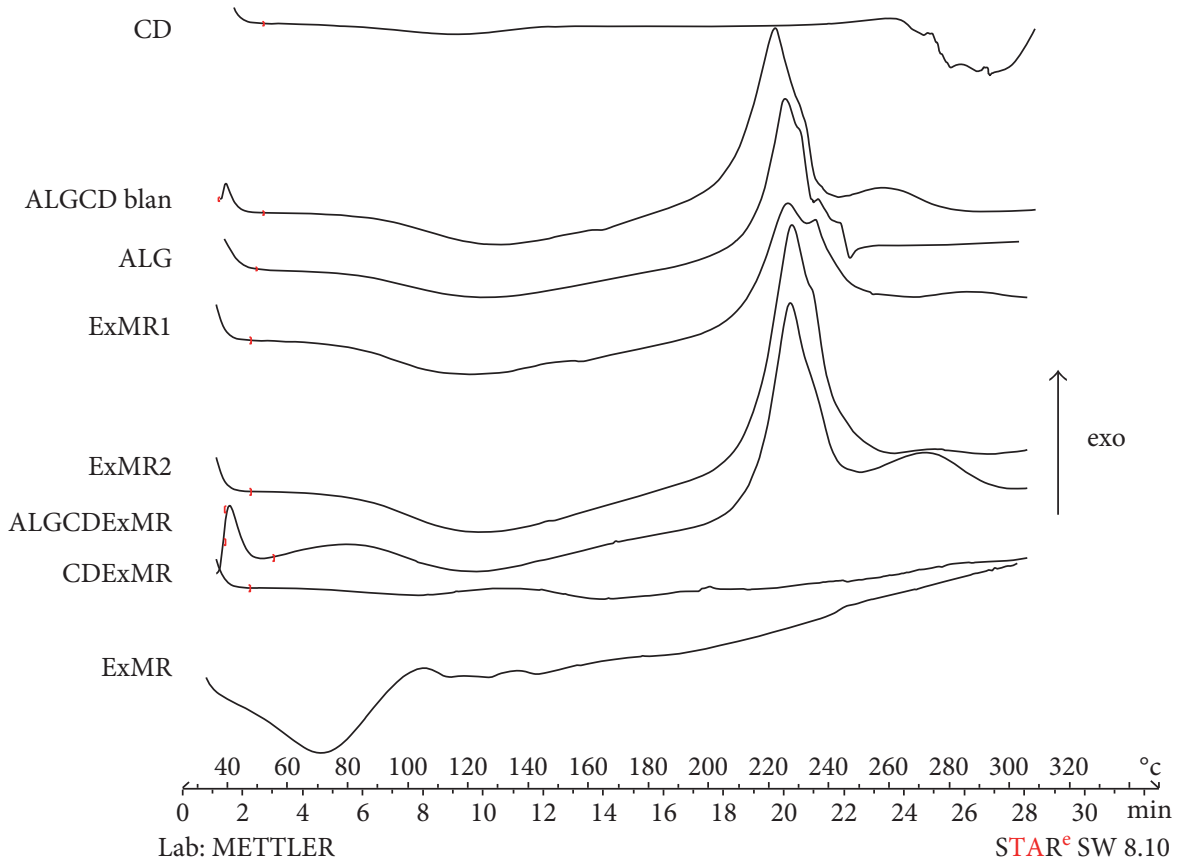

FIGURE 5: Differential scanning calorimetry of pure materials (ExMR, CD, and ALG), micropowders, blank (ALGCD blank), and loading microsystems (ExMR1, ExMR2, CDExMR, and ALGCDExMR).

3.4.2. Alginate/Cyclodextrin Microparticles (CDExMR and $A L G C D E x M R)$. The presence of CD reduces the particle size during the spray drying process and improves the EE (90.0$100.0 \%)$. In fact, the micrograph of the batches CDExMR and ALGCDExMR showed the presence of small microparticles
(Figures 4(c) and 4(d)) with dimensions of about $0.5 \pm 0.02$ and $1.0 \pm 0.2 \mu \mathrm{m}$, respectively.

The CDExMR thermogram shows a series of peaks from $180^{\circ} \mathrm{C}$ to $280^{\circ} \mathrm{C}$ which are superimposable with that of pure ExMR, with slight shifts. This behavior confirms that the 

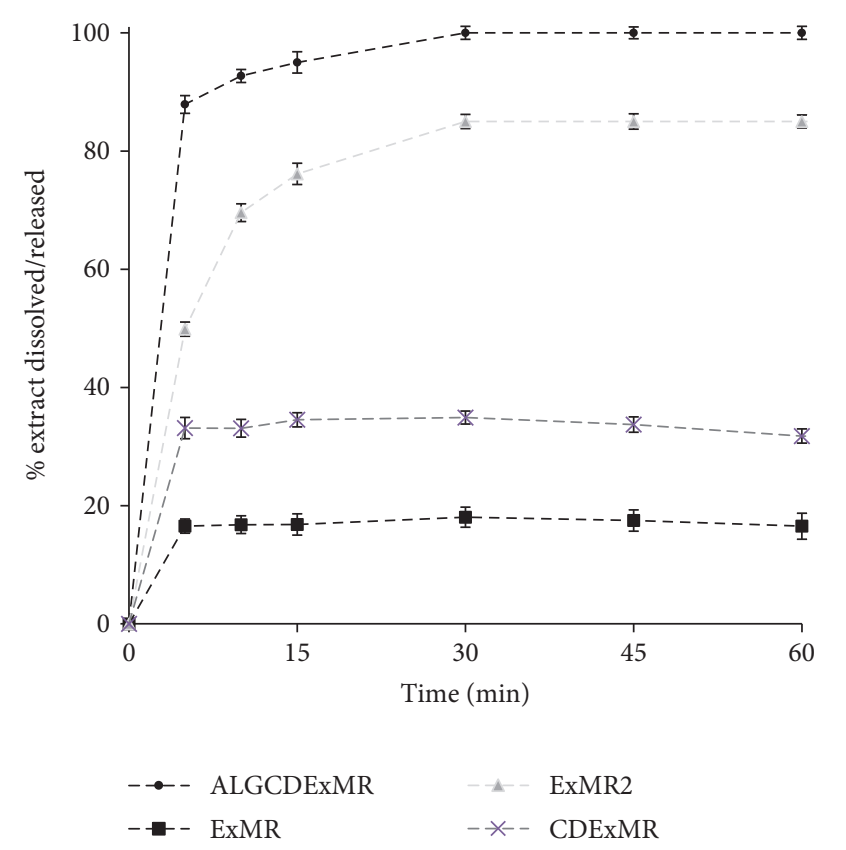

FIGURE 6: Dissolution/release profile of ExMR2, CDExMR, and ALGCDExMR in comparison with ExMR micropowder dissolution profiles in water.

1:1 CD/ExMR molar ratio is unable to form a complex. Instead, the shifts show that microparticle components interact only to form $-\mathrm{H}$ bonds, such as confirmed by FTIR spectroscopy (amplification of $\mathrm{OH}$ band at $3500 \mathrm{~cm}^{-1}$; data not shown) [47].

The $-\mathrm{H}$ bonds between $\mathrm{CD}$ and ExMR could be responsible of the enhancement of the extract dissolution rate. About 33.0\% of the extract dissolved from CDExMR in water after 5 minutes, with respect to about $16.0 \%$ of pure ExMR that dissolved at same time. Moreover, when used together, ALG and CD act synergistically enhancing the dissolution/release of ExMR (about 90\% after $5 \mathrm{~min}$ ) from ALGCDExMR, and all loaded doses were released $(100 \%$ in $30 \mathrm{~min})$.

3.5. Accelerated and Functional Stability (ICH Guidelines) and ORAC Test. The extract powders obtained from blood orange processing wastes are rich in polyphenols, easily subject to oxidation/degradation phenomena. This behavior is a critical point for their use in food or pharmaceutical field [48]. To examine the shelf life, the antioxidant efficiency and the effect of the ALG and CD polymers, and the microencapsulation processes on the stability of the extract in storage conditions, the "real-time" stability was reproduced according to $\mathrm{ICH}$ guidelines in a climatic chamber and in a brief time period in extreme conditions. The functional stability of ICH extract was performed by the ORAC assay.

After one week at $40^{\circ} \mathrm{C}$, an increase in ExMR weight, determined by the gravimetric method, was observed (28.0\%). This is probably due to its hygroscopicity. The quantitative ORAC and TPC also showed a significant decrease in the ExMR AOA (from 2.6 to 0.7 ORAC units) and TPC (about 12.0\%) (Table 3). Moreover, while CDExMR

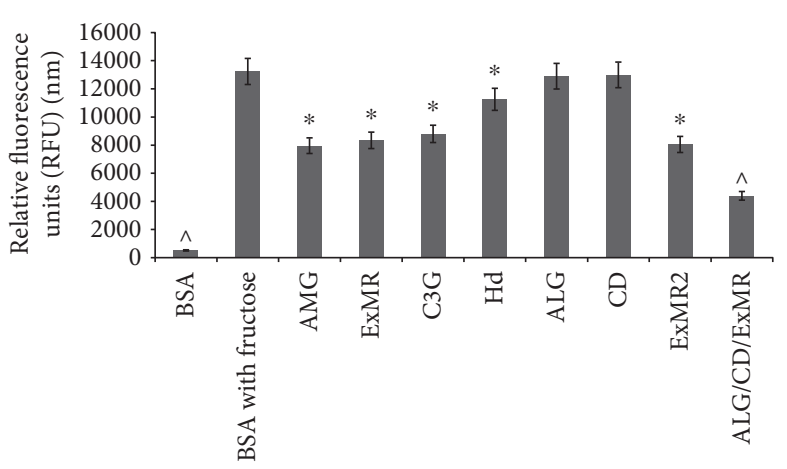

FIgURE 7: Antiglycation effect of unformulated and formulated extracts, Hd and C3G, major biopolyphenol compounds, in comparison with AMG assay standard control. Results are means \pm SD. Significantly different at ${ }^{*} p<0.05$ or $\hat{p}<0.01$ compared with positive control (BSA with fructose).

values slightly decreased (about 5.0\%), ExMR2 and ALGCDExMR remained quite unaltered, showing that this significant result in terms of stability $(<1 \%)$ is due to ALG that is able to enhance ExMR shelf life.

The decrease of ExMR data was probably due to thermal degradation of few polyphenols contained in citrus extract. In fact, literature data report that anthocyanins in blood orange juice presented high-rate constant of degradation in the range $30^{\circ}-90^{\circ} \mathrm{C}$ [49] with $69 \%$ losses after $90^{\circ}$ for $120 \mathrm{~min}$ [50]. Instead, for flavanones such as hesperidin, no significant decrease was noticed in the range $70-90^{\circ} \mathrm{C}$ after $240 \mathrm{~min}$ [51]. In fact, it was demonstrated that glycosidic flavonoids are more resistant than aglycone flavonoids to heat treatments [52].

3.6. Antioxidant Efficiency. The ORAC assay has been performed in order to evaluate the qualitative antioxidant efficiency of the best formulation, untreated and treated according to ICH. The data (Figure 1) showed that at 4 hours, ALG and CD slightly improve the ExMR antioxidant efficiency with respect to the unformulated extract, with a major effect for CD polymer. On the contrary, at 6 hours, ExMR and all the formulations without CD (ExMR2 and ExMR ICH) had lost their antioxidant efficiency. Indeed, ALG/CD/ExMR and ALG/CD/ExMR ICH maintain and prolong the extract activity only with a slow further spontaneous decomposition of fluorescein. These results suggest that the presence of $\mathrm{CD}$ in the microsystems preserved the antioxidant efficiency of the extract for a longer time and enhanced the stability of the extract.

3.7. Antiglycation Activity. The amount of AGEs is elevated during hyperglycemic and/or oxidative stress conditions [53]. This process induces irreversibly fluorescent macroprotein derivative formation, termed AGEs, via Maillard reaction [54]. Considering that a diet rich in natural antioxidant compounds protect against protein glycation [18], we evaluated the inhibitory effect of both unformulated and formulated extracts on fluorescent AGE formation. The results (Figure 7) showed a good ExMR capability to inhibit AGEs, reducing the max fluorescent value of positive 
TABLE 4: Inhibitory activity on MMP-2 and MMP-9.

\begin{tabular}{lcc}
\hline Compounds & $\mathrm{IC}_{50}$ MMP-2 $(\mu \mathrm{g} / \mathrm{ml})$ & $\mathrm{IC}_{50}$ MMP-9 $(\mu \mathrm{g} / \mathrm{ml})$ \\
\hline ExMR & $1.12 \pm 0.12$ & $5.52 \pm 0.72$ \\
ALG & n.a. & n.a. \\
CD & $4.03 \pm 0.35^{\wedge}$ & $2.98 \pm 0.31^{*}$ \\
Hd & n.a. & n.a. \\
C3G & $10.57 \pm 1.35^{\wedge}$ & $7.27 \pm 1.05$ \\
ExMR2 & $4.49 \pm 0.85^{\wedge}$ & $4.27 \pm 0.46^{*}$ \\
ALGCDExMR & $0.49 \pm 0.09^{\wedge}$ & $1.40 \pm 0.19^{\wedge}$ \\
\hline
\end{tabular}

n.a. $=$ not active $\left(\mathrm{IC}_{50}>100 \mu \mathrm{g} / \mathrm{ml}\right)$. Reported values are the means \pm standard deviation (SD) $(n=3) .{ }^{*} p<0.05$ compared to ExMR value. ${ }^{\wedge} p<0.01$ compared to ExMR value.

control (BSA with fructose) from $13,254 \mathrm{~nm}$ to $8338 \mathrm{~nm}$. This value corresponded to $37.0 \%$ of inhibition, and the observed effect is superimposable to that of the AMG assay standard (40.0\% of inhibition). Also, in order to determine which representative compounds influence the most the antiglycation effect, the ExMR activity was compared with those of C3G and $\mathrm{Hd}$, the selected representative standard compounds. Both samples are able to inhibit AGE formation, showing a fluorescence of $8798 \mathrm{~nm}$ and $11,249 \mathrm{~nm}$, respectively, corresponding to $36.3 \%$ and $15.2 \%$ of inhibition. This demonstrates that the ExMR activity is due to a synergic effect of both polyphenol class compounds (bioflavonoids and anthocyanins). Moreover, to evaluate the polymer effect, ExMR2 and ALGCDExMR were also tested. The major activity of formulation was found in ALGCDExMR with a fluorescence value of $4335 \mathrm{~nm}$, corresponding to $69.2 \%$ of inhibition, followed by ExMR2 with a fluorescence value of $8040 \mathrm{~nm}$, corresponding to $39.3 \%$ of inhibition. The results underline that all the formulations tested showed an AGE direct inhibition, indicating that both CD and ALG polymers are able to protect the extract from degradation and oxidation phenomena.

3.8. Inhibitory Activity on $M M P-2$ and MMP-9. AGE accumulation has a role in the increase of different metalloproteinase expression [18]. Because many polyphenol compounds inhibit both collagenase and gelatinase activities $[55,56]$, we evaluated the inhibition ability of the tested samples on MMP-2 and MMP-9.

The results reported in Table 4, expressed as the concentration value $(\mu \mathrm{g} / \mathrm{ml})$ of potential inhibitor that reduces of $50 \%$ the MMP activity $\left(\mathrm{IC}_{50}\right)$, showed that ExMR possesses a high capability to inhibit both MMP-2 and MMP-9. This could be due to the anthocyanin content. In fact, the representative flavonoid $\mathrm{Hd}$ is not active, while the anthocyanin $\mathrm{C} 3 \mathrm{G}$ has an $\mathrm{IC}_{50}$ value of $10.57 \pm 1.35 \mu \mathrm{g} / \mathrm{ml}$ and $7.27 \pm 1.05 \mu \mathrm{g} / \mathrm{ml}$ on MMP-2 and MMP-9, respectively.

In order to evaluate if the formulation can influence the activity of the pure extract, the inhibitory activity of formulated extract (ExMR2 and ALGCDExMR) and pure materials (ExMR, ALG and CD) were assayed. We observed that the presence of ALG in ExMR2 reduced the inhibition activity on MMP-2 $(4.49 \pm 0.85 \mu \mathrm{g} / \mathrm{ml})$, but improved the activity on MMP-9 $(4.27 \pm 0.46 \mu \mathrm{g} / \mathrm{ml})$, while the presence of CD in ALGCDExMR improved the inhibitory effect on both MMPs $(0.49 \pm 0.09 \mu \mathrm{g} / \mathrm{ml}$ and $1.40 \pm 0.19 \mu \mathrm{g} / \mathrm{ml}$ on MMP-2 and MMP-9, resp.) with respect to pure ExMR $(1.12 \pm 0.12 \mu \mathrm{g} / \mathrm{ml}$ and $5.52 \pm 0.72 \mu \mathrm{g} / \mathrm{ml}$, resp.). This could be explained with a high inhibition effect of CD on MMP-2 $(4.03 \pm 0.35 \mu \mathrm{g} / \mathrm{ml})$ and MMP-9 $(2.98 \pm 0.31 \mu \mathrm{g} / \mathrm{ml})$, probably due to the presence of free hydroxyl groups that support the hydrogen bond with the enzyme-active site [57].

\section{Conclusions}

An easily spray-dried handle antioxidant extract (ExMR) was produced to formulate dietary supplements for human health as well-formed and stable microparticles of ALG and CD also to make it suitable to be added in baked goods as bioactive food ingredients. The bioactivity on dysmetabolic disease was due to extract polyphenol compounds. In fact, anthocyanins and bioflavonoids both resulted responsible for the dried extract in vitro AGE inhibition activity, while only the anthocyanin content was effective with respect to in vitro MMP inhibition. Also, CD and ALG polymers were able to improve these activities. On one hand, $\mathrm{CD}$ improved the MMP inhibitory activity of the extract presumably because of the presence of free hydroxyl groups that support the hydrogen bond with the enzyme-active site; on the other hand, CD acted synergistically with ALG enhancing the dissolution/release of ExMR and improving the in vitro AGE direct inhibition of extract, also protecting it from degradation and oxidation phenomena. Furthermore, CD preserved the extract antioxidant efficiency and stability, while the choice of $2 \%$ of ALG as coated polymer (3:1 ALG/ExMR weight ratio) was effective to improve the extract wettability and its shelf life.

This research represents an advantageous way to reevaluate a blood orange citrus by-products of the Sicilian industry and to develop human dietary supplement which also acts to be added as "bioactive food ingredients" in functional foods like baked goods.

\section{Conflicts of Interest}

The authors declare that there are no competing interests regarding the publication of this paper.

\section{Acknowledgments}

The authors would like to thank the Sicily region for the financial support within PO FESR Sicilia 2007-2013, "ALIFUIDEA: Alimenti Funzionali e Integratori Nutraceutici a base di Lupino bianco e derivati di Agrumi" (ALIFUIDEA Project. "Functional Food and Nutraceutical Supplements with Bioactive Compounds from Citrus Fruit and LupineBased Ingredients").

\section{References}

[1] C. M. Galanakis, "Recovery of high added-value components from food wastes: conventional, emerging technologies and commercialized applications," Trends in Food Science \& Technology, vol. 26, pp. 68-87, 2012. 
[2] P. Rapisarda, S. E. Bellomo, and F. Intrigliolo, "Anthocyanins in blood oranges: composition and biological activity," in Recent Research Developments in Agricultural and Food Chemistry, S. G. Pandalai, Ed., vol. 5, pp. 217-230, Research Signpost, Trivandrum, India, 2001.

[3] P. Rapisarda, A. Tomaino, R. Lo Cascio, F. Bonina, A. De Pasquale, and A. Saijia, "Antioxidant effectiveness as influenced by phenolic content of fresh orange juices," Journal of Agricultural and Food Science, vol. 47, pp. 4718-4723, 1999.

[4] P. Rapisarda, S. Fabroni, S. Peterek, G. Russo, and H. P. Mock, "Juice of new citrus hybrids (Citrus clementina Hort. ex Tan. $\times$ C. sinensis L. Osbeck) as a source of natural antioxidants," Food Chemistry, vol. 117, no. 2, pp. 212-218, 2009.

[5] A. M. Panico, F. Garufi, S. Nitto et al., "Antioxidant activity and phenolic content of strawberry genotypes from Fragaria x ananassa," Pharmaceutical Biology, vol. 47, no. 3, pp. 203208, 2009.

[6] M. R. Lauro, L. Crasci, C. Carbone, R. P. Aquino, A. M. Panico, and G. Puglisi, "Encapsulation of a citrus by-product extract: development, characterization and stability studies of a nutraceutical with antioxidant and metalloproteinases inhibitory activity," LWT-Food Science and Technology, vol. 62, no. 1, pp. 169-176, 2015.

[7] M. R. Lauro, L. Crascí, F. Sansone, V. Cardile, A. M. Panico, and G. Puglisi, "Development and in vitro evaluation of an innovative "dietary flavonoid supplement" on osteoarthritis process," Oxidative Medicine and Cellular Longevity, vol. 2017, Article ID 7503240, 10 pages, 2017.

[8] F. Salamone, G. Li Volti, L. Titta et al., "Moro orange juice prevents fatty liver in mice," World Journal of Gastroenterology, vol. 18, no. 29, pp. 3862-3868, 2012.

[9] L. Titta, M. Trinei, M. Stendardo et al.I. Berniakovich, K. Petroni, C. Tonelli et al., "Blood orange juice inhibits fat accumulation in mice," International Journal of Obesity, vol. 34, no. 3, pp. 578-588, 2010.

[10] F. Sansone, T. Mencherini, P. Picerno, M. d'Amore, R. P. Aquino, and M. R. Lauro, "Maltodextrin/pectin microparticles by spray drying as carrier for nutraceutical extracts," Journal of Food Engineering, vol. 105, no. 3, pp. 468-476, 2011.

[11] E. B. Rodriguez, M. E. Flavier, D. B. Rodriguez-Amaya, and J. Amaya-Farfán, "Phytochemicals and functional foods. Current situation and prospect for developing countries," Segurança Alimentar e Nutricional, vol. 13, no. 1, pp. 1-22, 2006.

[12] C. Soukoulis, L. Yonekura, H. H. Gan, S. Behboudi-Jobbehdar, C. Parmenter, and I. Fisk, "Probiotic edible films as a new strategy for developing functional bakery products: the case of pan bread," Food Hydrocolloids, vol. 39, no. 100, pp. 231242, 2014.

[13] J. R. Paxman, J. C. Richardson, P. W. Dettmar, and B. M. Corfe, "Daily ingestion of alginate reduces energy intake in free-living subjects," Appetite, vol. 51, no. 3, pp. 713-719, 2008.

[14] D. Houghton, M. D. Wilcox, P. I. Chater, I. A. Brownlee, C. J. Seal, and J. P. Pearson, "Biological activity of alginate and its effect on pancreatic lipase inhibition as a potential treatment for obesity," Food Hydrocolloids, vol. 49, pp. 18-24, 2015.

[15] M. R. Lauro, C. Carbone, F. Sansone et al., "Innovative oral spray-dried idebenone systems to improve patient compliance," Drug Development and Industrial Pharmacy, vol. 42, no. 7, pp. 1127-1136, 2016.

[16] M. R. Lauro, C. Carbone, R. Auditore et al., "A new inclusion complex of amlodipine besylate and soluble $\beta$-cyclodextrin polymer: preparation, characterization and dissolution profile," Journal of Inclusion Phenomena and Macrocyclic Chemistry, vol. 76, no. 1-2, pp. 19-28, 2013.

[17] A. Nasir, S. L. Harikumar, and K. Amanpreet, "Cyclodextrins: an excipient tool in drug delivery: a review," International Research Journal of Pharmacy, vol. 3, no. 4, pp. 44-50, 2012.

[18] L. Crascì, M. R. Lauro, G. Puglisi, and A. Panico, "Natural antioxidant polyphenols on inflammation management: antiglycation activity vs metalloproteinases inhibition," Critical Reviews in Food Science and Nutrition, pp. 1-12, 2016.

[19] G. Derosa, P. Maffioli, A. D’Angelo et al., "Evaluation of metalloproteinase 2 and 9 levels and their inhibitors in combined dyslipidemia," Clinical and Investigative Medicine, vol. 32, no. 2, pp. 124-132, 2009.

[20] F. V. Romeo, G. Ballistreri, S. Fabroni et al., "Chemical characterization of different sumac and pomegranate extracts effective against Botrytis cinerea rots," Molecules, vol. 20, no. 7, pp. 11941-11958, 2015.

[21] R. L. Rouseff, S. F. Martin, and C. O. Youtsey, "Quantitative survey of narirutin, naringin, hesperidin, and neohesperidin in citrus," Journal of Agricultural and Food Chemistry, vol. 35, no. 6, pp. 1027-1030, 1987.

[22] O. A. Aiyegoro and A. I. Okoh, "Preliminary phytochemical screening and in vitro antioxidant activities of the aqueous extract of Helichrysum longifolium DC," BMC Complementary and Alternative Medicine, vol. 10, pp. 21-29, 2010.

[23] P. Rapisarda, F. Fanella, and E. Maccarone, "Reliability of analytical methods for determining anthocyanins in blood orange juices," Journal of Agricultural and Food Chemistry, vol. 48, no. 6, pp. 2249-2252, 2000.

[24] T. K. Higuchi and A. Connors, "Phase-solubility techniques," Advances in Analytical Chemistry and Instrumentation, vol. 4, pp. 117-212, 1965.

[25] F. Sansone, P. Picerno, T. Mencherini et al., "Flavonoid microparticles by spray-drying: influence of enhancers of the dissolution rate on properties and stability," Journal of Food Engineering, vol. 103, no. 2, pp. 188-196, 2011.

[26] G. Cao, H. M. Alessio, and R. G. Cutler, "Oxygen-radical absorbance capacity assay for antioxidants," Free Radical Biology and Medicine, vol. 14, no. 3, pp. 303-311, 1993.

[27] C. Puglia, V. Cardile, A. M. Panico et al., "Evaluation of monooleine aqueous dispersions as tools for topical administration of curcumin: characterization, in vitro and ex-vivo studies," Journal of Pharmaceutical Sciences, vol. 102, no. 7, pp. 2349-2361, 2013.

[28] C. Puglia, M. R. Lauro, A. Offerta et al., "Nanostructured lipid carriers (NLC) as vehicles for topical administration of sesamol: in vitro percutaneous absorption study and evaluation of antioxidant activity," Planta Medica, vol. 83, no. 5, pp. 398-404, 2016.

[29] S. Derbré, J. Gatto, A. Pelleray, L. Coulon, D. Séraphin, and P. Richomme, "Automating a 96-well microtiter plate assay for identification of AGEs inhibitors or inducers: application to the screening of a small natural compounds library," Anaytical and Bioanalytical Chemistry, vol. 398, no. 4, pp. 1747-1758, 2010.

[30] D. Edelstein and M. Brownlee, "Mechanistic studies of advanced glycosylation end product inhibition by aminoguanidine," Diabetes, vol. 41, no. 1, pp. 26-29, 1992.

[31] L. Crascì, P. Vicini, M. Incerti, V. Cardile, S. Avondo, and A. Panico, "2-Benzisothiazolylimino-5-benzylidene-4- 
thiazolidinones as protective agents against cartilage destruction," Bioorganic and Medicinal Chemisty, vol. 23, no. 7, pp. 1551-1556, 2015.

[32] M. D. L. M. Bilbao, C. Andrés-Lacueva, O. Jáuregui, and R. M. Lamuela-Raventos, "Determination of flavonoids in a citrus fruit extract by LC-DAD and LC-MS," Food Chemistry, vol. 101, no. 4, pp. 1742-1747, 2007.

[33] S. Hillebrand, M. Schwarz, and P. Winterhalter, "Characterization of anthocyanins and pyranoanthocyanins from blood orange [Citrus sinensis (L.) Osbeck] juice," Journal of Agricultural and Food Chemistry, vol. 52, no. 24, pp. 7331-7338, 2004.

[34] S. R. Georgetti, R. Casagrande, C. R. F. Souza, W. P. Oliveira, and M. J. V. Fonseca, "Spray drying of the soybean extract: Effects on chemical properties and antioxidant activity," LWT-Food Science and Technology, vol. 41, no. 8, pp. 15211527, 2008.

[35] R. R. Araujo, C. C. C. Teixeira, and L. A. P. Freitas, "The preparation of ternary solid dispersions of an herbal drug via spray drying of liquid feed," Drying Technology, vol. 28, no. 3, pp. 412-421, 2010.

[36] C. R. F. Souza, I. A. Schiavetto, F. C. F. Thomazini, and W. P. Oliveira, "Processing of Rosmarinus officinalis linne extract on spray and spouted bed dryers," Brazilian Journal of Chemical Engineering, vol. 25, no. 1, pp. 59-69, 2008.

[37] R. L. Carrier, L. A. Miller, and I. Ahmed, "The utility of cyclodextrins for enhancing oral bioavailability," Journal of Controlled Release, vol. 123, no. 2, pp. 78-99, 2007.

[38] N. Phisut, "Spray drying technique of fruit juice powder: some factors influencing the properties of product," International Food Research Journal, vol. 19, no. 4, pp. 1297-1306, 2012.

[39] M. R. Lauro, F. De Simone, F. Sansone, P. Iannelli, and R. P. Aquino, "Preparations and release characteristics of naringin and naringenin gastro-resistant microparticles by spraydrying," Journal of Drug Delivery Science and Tecnology, vol. 17, no. 2, pp. 119-124, 2007.

[40] P. Picerno, F. Sansone, T. Mencherini et al., "Citrus bergamia juice: phytochemical and technological studies," Natural Product Communinication, vol. 6, no. 7, pp. 951-955, 2011.

[41] G. P. Panizzon, F. G. Bueno, T. Ueda-Nakamura, C. V. Nakamura, and B. P. Dias Filho, "Preparation of spraydried soy isoflavone-loaded gelatin microspheres for enhancement of dissolution: formulation, characterization and in vitro evaluation," Pharmaceutics, vol. 6, no. 4, pp. 599-615, 2014.

[42] A. C. Templeton, S. R. Byrn, R. J. Haskell, and T. E. Prisinzano, Discovering and Developing Molecules with Optimal Drug-Like Properties, Springer, New York, NY, USA, 2015.

[43] B. B. Patel, J. K. Patel, S. Chakraborty, and D. Shukla, "Revealing facts behind spray dried solid dispersion technology used for solubility enhancement," Saudi Pharmaceutical Journal, vol. 23, no. 4, pp. 352-365, 2015.

[44] S. Jana, K. Trivedi, R. M. Tallapragada et al., "Characterization of physicochemical and thermal properties of chitosan and sodium alginate after biofield treatment," Pharmaceutica Analytica Acta, vol. 6, pp. 1-10, 2015.

[45] J. P. Soares, J. E. Santos, G. O. Chierice, and E. T. G. Cavalheiro, "Thermal behavior of alginic acid and its sodium salt," Eclética Química, vol. 29, no. 2, pp. 57-64, 2004.

[46] M. B. Nieto, "Structure and function of polysaccharide gumbased edible films and coatings," in Edible films and Coatings for Food Applications, K. C. Huber and M. E. Embuscado, Eds., Springer, New York, NY, USA, 2009.
[47] F. Sansone, A. Rossi, P. Del Gaudio, F. De Simone, R. P. Aquino, and M. R. Lauro, "Hesperidin gastroresistant microparticles by spray-drying: preparation, characterization, and dissolution profiles," AAPS PharmSciTech, vol. 10, no. 2, pp. 391-401, 2009.

[48] P. Laine, P. Kylli, M. Heinonen, and K. Jouppila, "Storage stability of microencapsulated cloudberry (Rubus chamaemorus) phenolics," Journal of Agricultural and Food Chemistry, vol. 56, no. 23, pp. 11251-11261, 2008.

[49] M. Cisse, F. Vaillant, O. Acosta, C. Dhuique-Mayer, and M. Dornier, "Thermal degradation kinetics of anthocyanins from blood orange, blackberry, and roselle using Arrhenius, Eryng, and Ball models," Journal of Agricultural and Food Chemistry, vol. 57, no. 14, pp. 6285-6291, 2009.

[50] A. Kirca and B. Cemeroglu, "Degradation kinetics of anthocyanins in blood orange juice and concentrate," Food Chemistry, vol. 81, pp. 583-587, 2003.

[51] C. Dhuique-Mayer, M. Tbatou, M. Carail, C. Caris-Veyrat, M. Dornier, and M. J. Amiot, "Thermal degradation of antioxidant micronutrients in citrus juice: kinetics and newly formed compounds," Journal of Agricultural and Food Chemistry, vol. 55, no. 10, pp. 4209-4216, 2007.

[52] H. Chaaban, I. Ioannou, I. Chebil et al., "Effect of heat processing on thermal stability and antioxidant activity of six flavonoids," Journal of Food Processing and Preservation, vol. 41, no. 5, pp. 1-12, 2017.

[53] J. W. BaynesS. R. Thorpe, "Glycoxidation and lipoxidation in atherogenesis," Free Radical Biology and Medicine, vol. 28, no. 12, pp. 1708-1716, 2000.

[54] S. I. Yamagishi, N. Nakamura, M. Suematsu, K. Kaseda, and T. Matsui, "Advanced glycation end products: a molecular target for vascular complications in diabetes," Molecular Medicine, vol. 21, Supplement 1, pp. S32-S40, 2015.

[55] L. Crascì and A. Panico, "Protective effects of many citrus flavonoids on cartilage degradation process," Journal of Biomaterilas and Nanobiotechnology, vol. 4, pp. 279-283, 2013.

[56] L. Crascì, L. Basile, A. Panico et al.S. Guccione et al., "Correlating in vitro target-oriented screening and docking: inhibition of matrix metalloproteinases activities by flavonoids," Planta Medica, vol. 83, no. 11, pp. 901-911, 2017.

[57] H. I. Park, S. Lee, A. Ullah, Q. Cao, and Q. X. A. Sang, "Effects of detergents on catalytic activity of human endometase/ matrilysin 2, a putative cancer biomarker," Analytical Biochemistry, vol. 396, no. 2, pp. 262-268, 2010. 


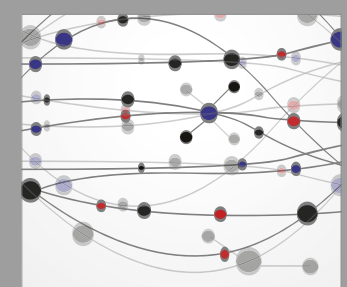

The Scientific World Journal
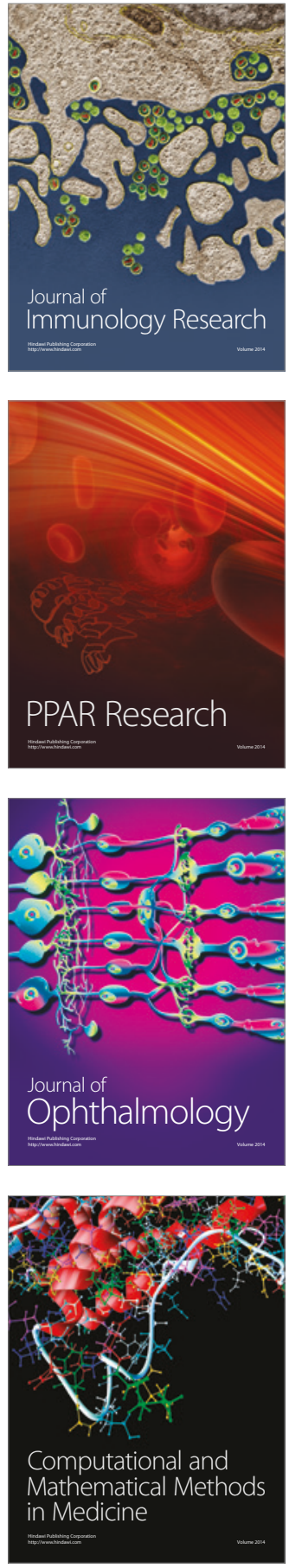

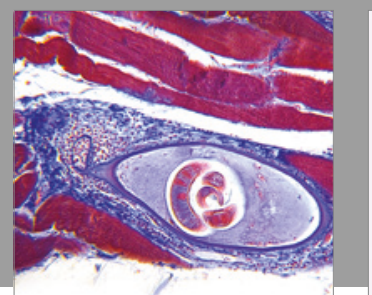

Gastroenterology Research and Practice
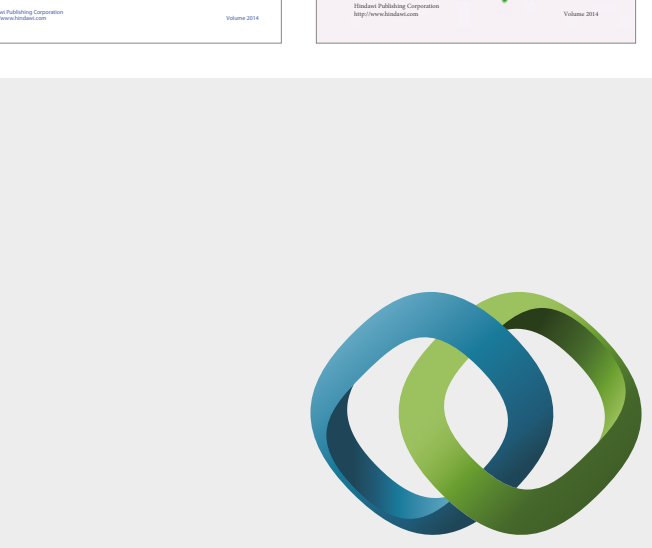

\section{Hindawi}

Submit your manuscripts at

https://www.hindawi.com
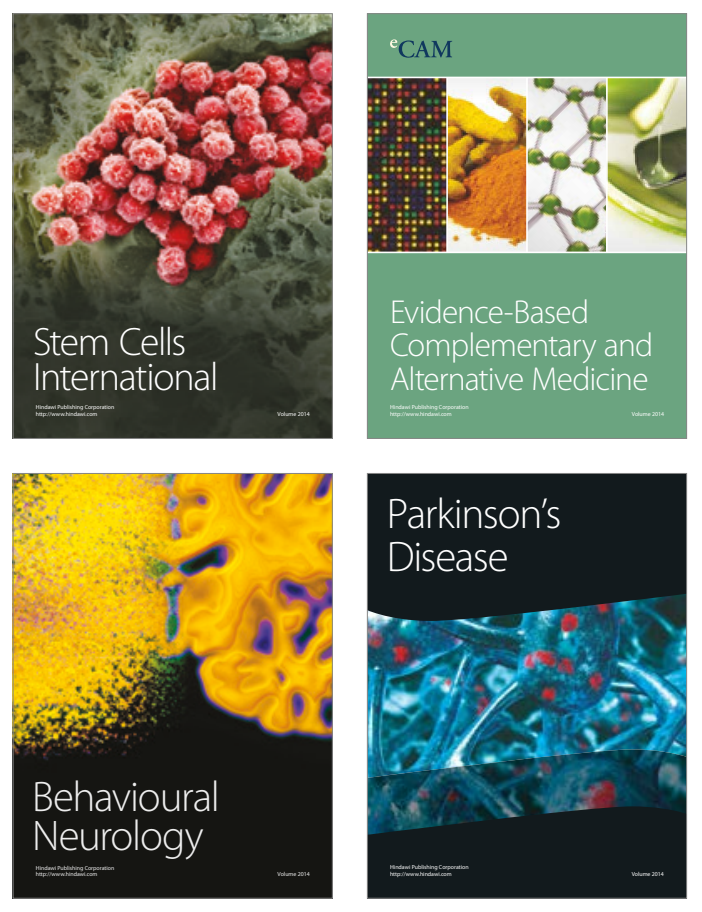
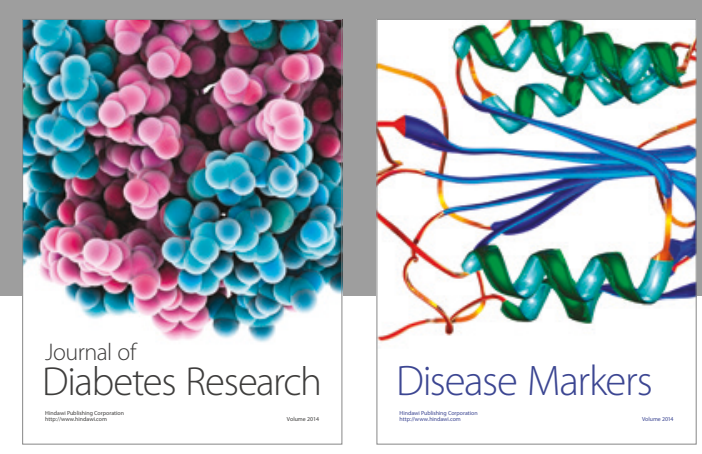

Disease Markers
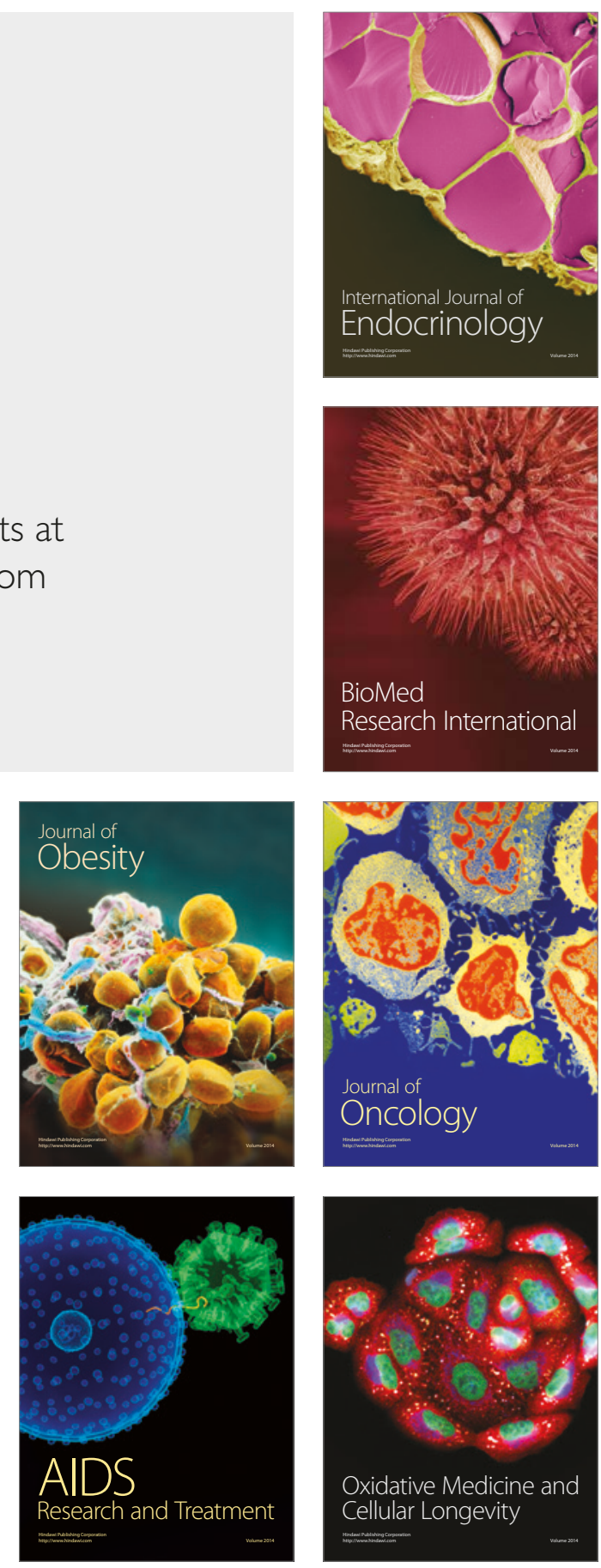